\title{
Motherhood and the Military, Apposing Forces? A Female Perspective
}

\section{Orla Jennings}

Becoming a mother is a life altering experience on its own. When women who serve in the military become mothers for the first time their cover as conceptual men is broken. Motherhood ultimately alters the playing field. This article explores the challenges of motherhood within the military. It investigates how women serving in the Irish Defence Forces navigate work life balance in a male dominated organisation as they undertake the most female role of all motherhood. It explores issues that arise before during and after pregnancy and how the Defence Forces responds. The White Paper on Defence published in 2015 , made a commitment to continue to progress work life balance initiatives for all members of the organisation (Department of Defence, 2015).This paper provides a valuable opportunity to generate narratives that have not been heard in the organisation before in response to this commitment.

This study confirmed that women re-evaluate their future careers when children arrive and based on current requirements for career progression within the Defence Forces are self-selecting not to progress. It also confirmed that the current career obstacles for many to overcome require a clear choice between family and work. This research drew attention to the fact that women are disadvantaged by common practices of performance appraisal when absent for maternity leave. This research has also demonstrated that women are highly committed to the Defence Forces and deeply appreciated of the statutory entitlements they receive. The article argues that, for the Irish Defence Forces to recruit, retain, promote and increase the number of women within the organisation, it is essential for it to acknowledge that the current practices do not fit with the way that women work. Failure to do so will continue to result in a loss of capability which the Defence Forces cannot afford.

Becoming a mother and continuing to pursue a career is arguably the most challenging professional experience that most women will encounter. For many Motherhood is the single most amazing event and the single most detrimental career experience at the same time. For the first time women are confronted with what appears an impossible task, the necessity to divide themselves between their work and their new child. This is a period of immense change when women are required to juggle their previous workload with the new responsibilities of being a mum for the first or subsequent time. This challenge takes on a new dimension when women work in the Irish Defence Forces, an organisation which is 94 percent male. Research 
highlights how women who work in male dominated organisations already experience higher levels of visibility and scrutiny of their performance, additional pressure to do well and social isolation (Yoder, 1991). Within the Irish Defence Forces previous research by Carrol (2013) and Clear (2017) has identified the negative experiences of women as a minority grouping. Thus, engagement with women around all these issues is critical. Conversations about gender and the value and importance of women is even more relevant in an organisation which is struggling to attract and retain women.

Motherhood is likely to be a time when women question work life balance. Prior to this, it is probable that women have been able to behave as conceptual men at work (Snitow, 1990). Women in the military may encounter the complexity of embracing motherhood and remaining true to their ambitions. These ambitions are what attracted them to a career in the military and they involve overseas service, deployments away from home and residential career courses. Added to this, is the difference in meaning of work to women. As Hewlett (2007) argued “Women's aspirations are constructed and fuelled in multidimensional ways. Women seek meaning and connection in their work lives and are less focused on money and power than their male peers". This does not diminish their ambitions. For those women who had been highly engaged with their professional careers prior to becoming mothers and maternity leave, post maternity leave this immense desire to progress and pursue their career remains. But for many a pause is needed. This research intends to determine if women within the Defence Forces have made decisions as a result of motherhood for individual or organisational reasons that have an unforeseen impact on their future careers and on the organisation.

The first woman joined the Irish Defence Forces in 1980 and women became fully integrated into the organisation in 1993. Today, women are represented across all Services, Corps and Formations and serve at home and overseas. In 2019 women in the Defence Forces comprised 6.9 percent of the organisation (Department of Defence and Defence Forces, 2019) of which 50 percent were mothers. The majority if not all of those that are mothers would have had their children while serving in the Defence Forces.

\section{Irish Maternity Legislation and Defence Forces Policy}

Maternity leave and the entitlement to maternity leave, is provided for by the Maternity Protection Act, 1994 and the Maternity Protection (Amendment) Act, 2004. Statutory Instrument (S.I.) 446/1994 Safety, Health and Welfare at Work Regulations (Pregnant Employees) and S.I. No.51/2006- Maternity Protection Act 1994 (Extension of Periods of Leave) Order 2006, provide additional details in respect of entitlements bestowed upon pregnant women in Ireland. Under this legislation the maximum entitlement for a pregnant employee is for 26 consecutive weeks of leave. Supplementary to this, an individual may take an additional 16 weeks of unpaid maternity leave. Two additional weeks of paid paternity leave are available since the first of November 2019.

The Irish Defence Forces are compliant with all the current Irish maternity legislation. Women serving in the Defence Forces avail of both the minimum paid entitlement and the additional unpaid entitlement. The decision relating to the amount of maternity leave a woman takes is a personal choice and is fully accommodated by the Defence Forces.

In 2015 the Defence Forces issued its first Defence Forces Maternity Policy in the form of a General Routine Order. This remains the substantive document on the issue within the 
Defence Forces. This policy aims to "outline policy, responsibilities and procedures for members of the Defence Forces who are planning a pregnancy, who become pregnant or who have recently given birth. It also outlines the responsibilities of Commanding Officers in the Defence Forces" (General Routine Order 04 of 2015, p.2). Within this document sections 20 and 21 which run to one and a half pages are dedicated to "After Maternity Leave". These sections primarily relate to assessing medical fitness post maternity leave, management of breastfeeding and the conduct of a return to work interview with an individual's Unit Commander or Head of Branch. One paragraph relates to duel service families and states that "the Defence Forces will endeavour not to deploy both serving parents of dependent children at the same time (unless they request otherwise), where this does not affect operational capability" (General Routine Order 04 of 2015, p.10). It then emphasises that "it is the service member's obligation to make their situation known to their Human Resources Section as soon as possible so that the situation can be examined in order to avoid unnecessary hardship on duel military families" (ibid). The existence of this document is a progressive step forward in recognising that policy and guidance are necessary to manage women both during and after pregnancy. However, there may be additional issues which are part of the normal experiences of women who return to work post maternity leave that are not captured in this document.

There is a gap in knowledge about the experiences of women who are mothers in the Defence Forces. This gap starts with their experiences during pregnancy, continues with their experiences on returning to work post maternity leave and extends to the juggle they encounter as working parents. To date this specific area has not been examined This article aims to address this gap and to generate new knowledge around this topic, thus creating ideas for additional supports for the management of women returning from maternity leave and identifying potential areas that needattention if both the number of women and the positions they fill are to increase.

The Irish Government's National Strategy for Women and Girls (2017-2020) lists for action the need "to promote initiatives to support women returning to work from maternity leave", in a separate section it also lists the need "...to identify any impediments to the advancement of women in the Permanent Defence Forces as well as the impact of the requirements of career courses and overseas service on female retention and advancement" (Department of Justice and Equality, 2017, p. 32, p.34). In an organisation that has expressed desire to increase the number of women from 6.9 percent to 12 percent (Department of Defence, 2015) every opportunity must be taken to determine if there are connections between the unique experiences' women face at work and retention and advancement.

It is worth noting, that 26 percent of successful pregnancy related cases decided through the Irish Equality Tribunal and the Labour Court from 1999 to 2008 related directly to women's treatment while on maternity leave or on their return to work after maternity leave (Carroll, 2018). The possibility of litigation for the Defence Forces places additional relevance on the information gained through this research. The knowledge gained from the experiences of women in the Defence Forces may be applicable to other organisations. Ultimately lessons identified within the Defence Forces may lead to better human resource management of not just women but also men in particular those that return to work after a significant period of absence. 


\section{PART ONE. Literature Review}

"Motherhood is widely considered to be a watershed in the careers of professional women particularly those working in male-dominated occupations." (Ranson, 2005, p. 145)

This review aims to identify the main themes in the literature, concerning women who work and become mothers, a pivotal experience in most women's lives as they experience the 'juggle' for the first time. It will begin by considering the institutions of work and family and examine the intersection between these two opposing arenas. Both institutions have been termed "greedy" by several writers (Coser, 1974; Harris, 2009), posing questions of role conflict as women attempt to balance competing demands. The construct of masculinity emerged as a constant throughout literature which examined gender. Following on from this work life balance and support systems within work will be explored with a consideration of perceived organisational support which feeds into the research experiences of women returning to work post maternity leave.

\section{Work and family: two competing systems}

Most workplaces and homes have different cultures and expectations (Morf, 1989). Clark (2000) has written of work and family as two systems that are different but interconnected. She suggests through her "work family border" theory that the connection between these two domains is the individual and "that people are border crossers who make daily transitions between two worlds - the world of work and the world of family" (Clark, 2000, p.748). Women are frequent border crossers who navigate between roles at work and roles at home. Levinson (1959) does not define roles as having a single meaning but rather they are constructed around responsibilities, personal perception and the environment in which an individual is functioning. Therefore, the greater the range and variety of roles an individual must perform the less time, energy and commitment there is to divide between these roles.

Roles experienced by women increase in number and variation when they become mothers. One of the major obstacles put forward for women in pursuing a career is that of balancing these new roles associated with motherhood and their previous existing work-related roles (Betz \& Fitzgerald, 1987). Betz and Fitzgerald (1987, p. 136) observe that participation at the same time in two activity systems such as work and the family that are "philosophically and practically incompatible" is a major difficulty in the career development of women.

Many authors (Ashforth, Kreiner \& Fugate, 2000; Clark, 2000; Schieman \& Gavin, 2008) designate the boundaries between work and home as permeable, and thus cross over between both these systems is inevitable. Permeability is the degree to which elements may get across the boundary and have an impact (Clark, 2000). The fact that boundaries are vulnerable to transfer from one area to another can make if difficult to manage work and family separately. The degree of permeability is somewhat irrelevant, it is its presence and existence that matters most. This has an impact for both the individual and the organisations for which they work. Several writers, (Ben \& Fitzgerald 1987; Clark 2000) discuss how work and family impact on each other and are keen to point out that organisations cannot ignore this because there is only a limited amount of resources to be shared between both. The difficulty arises when these two institutions are not content to share those resources. 
Coser (1974) views both work and family as greedy institutions. Greedy institutions have been defined as institutions that place a tenacious grip on individuals (Coser, 1974; Harris, 2009). According to Coser (1974, p. 4) "greedy institutions seek exclusive and undivided loyalty and they attempt to reduce the claims of competing roles and status positions on those they wish to encompass in their boundaries". In addition, military institutions can be described as "total institutions" (Harris, 2009). This means that the military can also place physical restrictions on an individual's location. The requirement to stay in a barracks or live in a particular camp overseas are examples of such restrictions. Soeters, Winslow and Weibull (2003) note that the military and the family fit the term "greedy institutions" since their continued existence depends significantly on the loyalty of their members. Thus, when a woman is a mother and a soldier, she is positioned within two competing systems. Both these systems demand her loyalty and conflict arises when a compromise is difficult to find.

\section{Work family conflict}

Work family conflict occurs when an individual is involved with two rival systems at the same time. Role conflict occurs as a result of having a range of competing duties to perform. There is a large degree of connection between both and it is not possible to discuss one without the other. Therefore, for the purpose of clarity they have been combined in this section.

Work family conflict has been defined as an interference with the performance of family related responsibilities by the demands of time devoted to work and the associated strain created from work (Netemeyer, 1996). Raskin (2006) observes that work family conflict is likely to occur when people care about the organisations they work for and their careers. Thus, those that experience the most intense conflict are frequently those that seek to perform exceptionally well at home and at work.

Kahn et al, (1964) define role conflict as mutually competing demands originating from several sources at once. Women experience a major change in both their identity and the demands on them after the birth of children (Levinson, 1996). These new demands establish new roles for women. Hall (1972) describes how the many competing roles filled by women gave rise to chronic role conflict.

Killian (1952) compares the various roles filled by both men and women and concludes that women experience greater role conflict due to the simultaneous nature of the operation of their roles. More recently, Daalen, Willemsen and Sanders (2006) summarise that a large amount of the research supports the presence of gender differences in how men and women experience role conflict. Southwell and MacDermid Wadsworth (2016) discuss how male and female service members experience similar events such as separation from family, geographical relocations and overseas deployment. They observe that there was a variation in experience and that these events effect men and women differently. If there are differences in how men and women experience similar events consideration may be needed to how these separations are managed.

Harris's (2009) research on female officers in the military portrays how the stress associated with filling duplicate roles of mother and professional conspires against women in their occupational journey towards promotion. Often this leads to a situation where the working mother feels she must succeed at everything "the woman should be a super housewife, a super mother, a super employee and a super wife" (Ciuperca, 2005, cited in 
Apostu 2017, p.2). Similarly, Apostu (2017) discusses the cost of women's desires to assert themselves socially and professionally when attempting to balance motherhood and career as having a detrimental effect and coins the term "role overcrowding" to describe this cost. Harris (2009) compares women who negotiate the career path in academia and those who are officers in the military as being on a similar trajectory.

The family has no boundaries on the level(s) of commitment that it exacts on its members... conflicts ensue and their associated tensions lead women to contrive strategies for success as they navigate the incompatible male career paths of their respective promotion and tenure systems. (Harris, 2009, p. 393)

Heneghan (2012) conducted a study focusing on female officers who were members of the $1^{\text {st }}$ to $66^{\text {th }}$ Cadet classes in the Irish Defence Forces. One of her conclusion's notes that the arrival of children acts as the turning point for the majority of these female officer's careers. She also notes that the participants in her study appear to hold "a bias about the compatibility of motherhood" and holding asenior appointment (Heneghan, 2012, p.39). It is worth highlighting that the female officers who participated in this study all served under terms and pension conditions which changed for cadet classes inducted after the $70^{\text {th }}$ Cadet class (commissioned as officers in 1995). These conditions provided for a larger pension after 20 years of service. This would have been a contributing factor for officers who retired early from those cadet classes. Interestingly, more recently Barrett (2018) confirms that motherhood remains as one the main challenges for the retention of senior female officers in the Irish Navy.

Segal (1986) acknowledges that women's inclusion in the military requires change by both the family and the military to diminish conflict that would be inevitable between both organisations. The ideal outcome is work-family balance where "satisfaction and good functioning exist at both work and home with minimum conflict" (Clark, 2000, p.751). If changes are necessary to re-balance work and family to minimise conflict any factors which contribute to the work environment should be analysed. Thus, when considering work and women, particularly within male dominated environments such as the military, we need to explore the concept of masculine organisations as relevant to the discussion.

\section{Issues of masculinity within masculine organisations}

Kronsell (2005, p.281) identifies military institutions as "institutions of hegemonic masculinity" due to the historical male exclusivity associated with the military. Hegemony refers to the dominance "achieved through culture, institutions and persuasion". Hegemonic masculinity embodies "the most honoured way of being a man" (Connell and Messerschmidt, 2005, p.832). Connell and Messerschmidt (2005) argue that at the top of the hierarchy of expressions of femininity and masculinity sits hegemonic masculinity. (Connell and Messerschmidt, 2005, p.832). Even with female participation, militaries are still largely male only spaces (Vuga, and Juvan 2013).

Taber (2009) writes that women in the military who become mothers are perceived as women and mothers before they are perceived as military members. Other authors such as (Kronsell, 2005) comment that women and men in the military are described differently, men 
are soldiers however women are female soldiers. Snitow (1990, p.26) describes how women who enter male dominated professions "enter not as women but as conceptual men". This idea was confirmed by many of the participants in both Carroll's (2013) and Clear's (2017) research on female members of the Irish Defence Forces. Snitow $(1990$, p.26) further elaborates that "this conceptual cover is blown when they (women) become or think about becoming mothers". Both Marshal (1984; cited by Ranson, 2005, p.146) and Gheradi (1996; cited by Ranson, 2005, p.146) pronounce women working in male dominated professions such as the military to be "travellers in a male world".

Kanter (1977) has described how the culture of an organisation is controlled and determined by the majority, which in the case of the military are men. Kanter (1977) claims that group ratios are linked to social experiences and that the ratio effects how minority groups are subsequently viewed. In organisations where women represent less than 15 per cent of the overall group, according to Kanter (1977) they frequently occupy the position of "token". This places those that fit into this category under additional scrutiny. They also feel greater pressure to perform well. There is a perception that when they act, they represent the group and not the individuals they are (Kanter, 1977).

Lewis and Simpson (2012) discuss how women may seek invisibility within male dominated workplaces as one solution to reduce effects of being identified as different. They further deliberate how women conform to the masculine norms within the workplace and even separate themselves from other women. These strategies are also well documented by other writers Ranson (2005) and Carroll (2013). As Taber has argued "the only way to become an old-timer is to conform to a masculine norm" (Taber, 2011, p.344). Old timers would be considered domain members within the work environment who hold a significant degree of influence. Linked with this is the fact that some mothers feel the need to hide their identity as mothers to fit into their work environment (Harris, 2009; Cahusac \& Kanji, 2014).

Ranson (2005) highlights the challenges for women in combining masculine professions and motherhood. She notes how, men who make up the majority of these workplaces, are not subject to the "same expectations regarding their family involvement" (Ranson, 2005, p.148). This is linked with cultural biases within society that can make it difficult for women to assume both roles of professional and mother (Harris, 2009). These cultural biases relate to the difficulty for some in accepting that women can be both mothers and professionals. For the most part society has moved forward considerably in the roles that both men and women can fill. However, some organisations like the military which remain a dominant masculine space may still hold unconscious biases in this area (Harris, 2009).

In a study conducted by Cahusac and Kanji (2014) of professional mothers working at managerial levels within masculine dominated organisations, they note that many mothers frequently set limits on how much they were prepared to follow previous working practices expected of senior appointment holders. Examples of this include hegemonic masculine methods of socializing outside of work hours which were seen as important events for networking and essential for career progression and the organising of meetings outside of work hours or at inconvenient times.

Morrissey (2018) talks of limitations being self-imposed by women on themselves, where they prevent themselves from reaching their potential. Carroll (2013) interestingly observed that the younger female officer participants in her study on female leadership in the 
Irish Defence Forces, had already given consideration to possible trade-offs they would have to make if they choose to have a family and a career.

Morrissey (2018) emphasised that efforts to assist women to fulfil their career potential must include providing additional choices to men. This requires taking a fresh look at gender equality and challenging our assumptions of traditional roles played by men and women. Morrissey (2018, p.59) speaks of "gender intelligent strategies" where organisations recognise the difference between men and women in the workforce and that progress requires an acceptance that we can be equal but different. She is keen to emphasise that difference does not equate to better or worse. Morrissey $(2018, p$. 78$)$ discourages the notion "that women need to be the same as men to be as good as men". Kronsell (2005) argues that while women represent a minority position within the military their very presence in itself highlights the difference and creates an awareness of the explicitly gendered norms that exist. This awareness is central to the development of policies and methods to address and support issues that affect both male and female members of military organisations.

Galinsky and Stein report that "Managers often state that developing formal and informal work/family supports requires a leap of faith, that what the company gives, it will get in return" (Galinsky and Stein, 1990, p378). Galinsky and Stein (1990) bracket organisations into either Stage 1 or Stage 2 on a scale of integration of work family balance policies. Stage 1 organisations are characterised by the following "a growing awareness of work/family issues, an identification of some employees' problems, the establishment of some programs and an overall piecemeal approach". Stage 2 organisations are described as having "comprehensive and multifaceted programs that were responsive to employees needs"(p378). The Irish Defence Forces could be described as fitting Galinsky and Stein's stage 1 description. The Defence Forces has some policies in the area and adopts a disjointed approach. Galinsky and Stein (1990) conducted analysis of 71 Fortune 500 corporations and view the main driver for commitment within those organisations to family friendly policies as the link made to improve both recruitment and retention. Both Raskin (2006) and Barrett (2018) also link retention of working mothers to both supportive policies and family friendly cultures. Recruitment and retention of women and men in the Irish Defence Forces has been a muchdiscussed challenge faced by the organisation (Department of Defence, 2015).

Repetti (1987) found that supportive relationships with supervisors is identified as the biggest influence on psychological well-being at work. 85 per cent of respondents in their survey were women and worked full time. Those individuals who had more choice in their decisions relating to work flexibility felt that balance between work and home was more easily attained. Hughes and Galinsky emphasise "Work family policies are ineffectual if supervisors do not support them" (Hughes \& Galinsky, 1988, p376). A study of 2000 employed women reported that supervisor support when returning to work post maternity leave was on par with having a supportive partner in its effect at reducing stress (Galinsky \& Stein, 1990). This study also provided clear links between work family supportive policies and reduced instance and frequency of sick leave during pregnancy, greater job satisfaction and working later into pregnancy. These results were found among the women who worked for the most accommodating organisations.

This choice may come with a price. A study conducted by Morrissey (2018) of 25,000 women in the UK in the 28-40 age bracket identifies flexible working practices as a method of achieving work life balance. However, only 40 per cent of those that participated felt that their 
employers associated flexible work practices with working efficiently. Clark (2000) also observes that there is a perception that employees who avail of flexible work solutions are taken less seriously and less likely to be offered opportunities for progression. Taber (2011) notes that some participants in her study felt that they were later penalised for availing of parental leave. Other authors, Cahusac and Kanji (2014) also acknowledge this. Family friendly policies designed to help balance work and family responsibilities come to be "perceived as helping women fit into men's workplaces" (Ranson, 2005, p. 163). The association of these policies with females is as a result of a lack of evidence of fathers employing these strategies to accommodate children.

A common thread running through the literature was that women, particularly those working in male dominated occupations, do not want special treatment but want to be managed better (Morrissey, 2018). Southwell and MacDermid Wadsworth (2016) highlight the issue that the military provided a range of support services but raised concerns as to whether the needs of female service members were met. They (p. 72) emphasise that an increase in the numbers of females in the military placed a greater importance on "understanding the unique characteristics of women's families". Carroll (2013) stresses in her conclusion that it was vital that those who design policy hear about the experiences of both men and women within the organisation.

\section{Perceived organisational support}

Perceived organisational support relates to employee's perception concerning the extent to which the organisation values their contribution and cares about their wellbeing (Kurtessis et al, 2015). An "employee's commitment to the organisation is strongly influenced by their perception of the organisations commitment to them" (Eisenberger, 1986, p. 500). This topic has been well discussed within the literature (Rhoades \& Eisenberger, 2002; Baran et al, 2012) and is recognised as producing favourable outcomes for both employees and employers. Lucia- Casademunt et al (2018) link this theory to positive experiences of women returning to work post maternity leave. Sandberg (2013) describes how women who return to work post maternity leave frequently do so with renewed energy and how organisations should be ready to embrace this. Perceptions of support by women returning to work after maternity leave have been found to affect their decisions (Glazer, 2006). This has significant implications for policy makers as the communication of supports is as important as actual practices.

Meglich, Mihelic and Zupan (2016) propose a model of perceived work-based support for motherhood. This model involves three sources of support: organisational, supervisor and co-worker. They determine based on their analysis, that "the work attitudes of mothers, may be influenced by how well supported they feel in the work environment which in turn may impact their performance and conduct of the job" (Meglich et al, 2016, p.35). This model provides a tool for considering the psychological aspects of support that could be missed if the focus is on written policies alone.

\section{Returning to work after maternity leave}

Returning to work post maternity leave is recognised within the literature as a key transition phase in a working woman's career (Langan, Sanders \& Agocs, 2017; Grether, Sowislo and Wiese, 2017; Lucia-Casademunt et al, 2018). This is a time when the art of balancing work, 
family and career reaches a climax. Various studies observe that when mothers perceive the organisational environment to be supportive, they are more committed to the workplace and frequently return to work quicker (Kelly et al, 2008). Lucia-Casademunt et al (2018) conducted a study across 27 European countries to look at the impact of work life balance on women after childbirth. Their sample consisted of over 1,300 employees with an almost even split between men and women, all with children under the age of one. One of their key findings is that work life balance and supervisor support positively influences the wellbeing of female employees after childbirth but is non- significant for men. This indicates that a key role exists for supervisors to engage with women regarding their return to work and that work life balance is an issue that becomes more relevant after the birth of children. Lucia- Casademunt et al (2018, p. 9) emphasise in their conclusions that "supervisors should be advised about their relevant role in the experiences of returning to work for both female and male employees". In an organisation that is predominantly male such as the Irish Defence Forces the roles played by supervisors and the importance of these roles may not be immediately obvious to those occupying these positions. Therefore, the need to establish these functions is even greater. It is clear from this research that human resource managers also have a key role to play.

Human resource managers and practitioners in firms in which women of childbearing age work should send clear signs to employees through different but simultaneously congruent human resource policies and practices that help them to face the uncertainty associated with their return to work after childbirth. (Lucia- Casademunt et al, 2018, p. 9)

A similar study although on a smaller scale was replicated across the Health Service Executive (HSE) (Carroll, 2018). In this study all but four participants concluded that they would not be progressing their career to the next level citing various reasons including the lack of support at higher levels. This study recommends that policies should be updated, support networks should be established and that organisational culture, attitudes and processes relating to women returning to work post pregnancy all need addressing. Sandberg (2013) and Portas (2018) also write about the changes in career choices of women after maternity leave but add the slant that women often make decisions' that are self-limiting.

In their study on Canadian police mothers, Langan et al (2017) found that women expressed the view that they felt that they had to prove themselves as an officer prior to becoming pregnant and that there existed a need to reprove themselves on returning to work post pregnancy. They also identify as a general theme that women often strove "to be one of the boys". These insights on proving oneself and of blending in are consistent with research done by Heneghan (2012) and Carroll (2013) on women who serve in the Irish Defence Forces and have been discussed above. However, it is possible that these themes act in some way to compound an already complex path that women returning to work post pregnancy must navigate. The idea of female members within male dominated organisations having to work harder to prove themselves post maternity leave also comes to the fore in research undertaken by Taber (2011). Ranson's (2005) study on mothers returning to work after maternity leave in highly male dominated engineering organisations found that women felt in a better position to negotiate for changes to accommodate their new family responsibilities, after they had achieved certain standards. These standards had been set by men. It was described as "money to cash in when needed" (Ranson, 2005, p.157).

Barrett (2018) determines that the Irish Naval Service should acknowledge the 
challenges facing women returning to work after maternity leave and assist them with the transition back to work. Several authors (Bussell, 2008; Beacom, 2013; Morrissey, 2018) discuss measures that could assist in breaking down barriers to reintegration to work after maternity leave, such as keep in touch days while on leave; a buddy programme where individuals choose a mentor who had been through maternity leave; and maternity coaching, where women are coached prior to, during and after maternity leave. However, overall literature on this subject provides little evidence on proactive support for women returning to work. Gatrell (2013) concludes in her research, which focuses on professional working women that none of those she interviewed reported receiving pro-active support from their employers in relation to how they would manage their careers on returning to work after maternity leave.

The literature revealed that women navigate between two greedy institutions, work and family, and substantial cross over occurs between both. This generates role conflict as women switch between the many roles they fill. Added to this, in the military environment is the competition between self as mother as self as soldier. The literature has shown that work life balance supports, and policies can provide avenues to generate balance, but they must be fit for purpose and supported from above. However, this is complicated by the fact that these structures are viewed as soft options for females differentiating them further from their male counterparts and in some way implying that they are less valued. It is the value that employees perceive that an organisation holds for them, which acts as a tool for recruitment, commitment and retention.

There is some conflict between the concept of "self-imposed ceilings" and those imposed by the hegemonic masculine culture of male dominated organisations. What role do women play in generating their own narratives about what happens when they become mothers? Are they fully cognisant of both the internal and external influences that affect the decisions they make? Do organisations need to do more to demonstrate that they value their employees in addition to offering written policies? These areas require further exploration. This paper will focus on the particular experiences of women in the Irish Defence Forces from the time they return to work after maternity leave to their views and encounters with work as mothers.

\section{PART TWO. Research methodology}

The data collection methods selected for this paper were focus groups and semi- structured interviews. Two focus groups were conducted utilising purposive sampling. The Women's Support Network, which was established in 2017 in the Defence Forces, was used as a vehicle to seek volunteers from across the organisation to participate in the focus groups. The criteria for participation was open to both commissioned and non-commissioned officers who became mothers while serving in the Defence Forces. 14 female personnel volunteered to participate. They ranged in rank from Corporal to Commandant. All three services of the Defence Forces Army, Air Corps and Naval Service are represented. Each participant had between one and five children. The children of the participants ranged in age from one year to 19 years. Their personal circumstances varied greatly. Duel service couples, single parents and the traditional family unit of two parents, a mother and father, both married and unmarried, were all represented within the focus groups. This diversity brought a broad perspective to the topic. The level of education ranged within the groups from leaving certificate to master's level with the majority holding a level eight qualification or equivalent.

Two semi- structured interviews were also conducted. Participants were chosen, on 
the basis of their positional influence on policy which relates to the question. The individual's selected represented senior HR management within the Defence Forces and within the Health Service Executive (HSE). The senior manager from the HSE was identified as it became apparent during the literature review that the HSE had recently conducted research around the experiences of women returning to work post maternity leave. 79 percent of HSE employees are female (Carroll, 2018). This places the HSE as an organisation which would provide an interesting comparison for the Defence Forces. The questions were constructed in consideration of the themes generated through the literature review and in conjunction with information gained from the focus groups. All questions were analysed to ensure their relevance to the research question. The focus groups and semi-structured interviews were digitally recorded and later transcribed. These transcripts were then coded in correlation with themes that emerged from the literature review. The themes selected were those that provided for the most insightful exploration of the experiences of women who navigate between motherhood and the military.

\section{PART THREE. Research findings}

This part will present the findings of the research undertaken with female members of the Defence Forces concerning their experiences of becoming mothers while serving. The narratives and themes extracted from their contributions are set out here. The interviews conducted with HRM appointment holders both from within the Defence Forces and the HSE at senior management level, are utilised to provide a backdrop and depth to their accounts where pertinent.

\section{The Defence Forces as a masculine organisation}

When considering the interaction, between women who become mothers and their employment in the military, issues with masculine organisations came to the fore. Kronsell (2015) describes this as the background environment within which the military operates. It was observed by this researcher that a conversation within such an organisation would be difficult. This primarily relates to the reality that motherhood is not an issue that affects the greater part of the organisation. It was apparent from the initial discourse within the focus groups that many of the women did not want to draw attention to anything that differentiated them from their male colleagues. In fact, they were initially keen to minimise the topic. However, it was noted as the focus groups progressed and the discourse developed, with experiences being shared responses changed. Participants acknowledged this was a legitimate subject, one which had deeply affected them. Lewis and Simpson (2012) describe this as how women seek to be invisible in male dominated organisations. It has been explained as a natural response by Kanter (1977) for individuals who find themselves in a minority grouping. This was most evident amongst respondents who were from the army. Perhaps this is because within the army, there is the greatest perceived need to blend in. One possible explanation may be that the army is the largest service and thus specialisation is more diluted. The most experienced participants were able to contextualise this experience. "It takes experience and maturity to find your place and build reliance to accept that men and women are different and that's ok" (FG2P6). All the women interviewed were eager to stress their gratitude for access to statutory maternity leave, additional unpaid maternity leave and parental leave. This is intriguing and indicative of the need to be invisible. 
There was a stark difference in the responses to questions on the impact of motherhood from the senior HR manager in the Defence Forces and the senior HR manager in the HSE. The senior HR manager in the HSE was a woman who was also a mother and coordinated HR in an organisation in which 78 percent of the employees are female. Both respondents were extremely professional and generous with their time. It was clear that the subject had greater resonance with the senior civilian HR manager. The senior HR manager from the Defence Forces has spent his entire career in a male dominated masculine organisation. It is likely that this has influenced his view on the subject of motherhood and the military.

\section{Becoming a mother in the military}

The serving commissioned and non-commissioned officers who took part in this research identified a range of issues they experienced when returning to work after maternity leave. These include the need for support, apprehension, the need for some to reacquire their confidence and physical concerns over breastfeeding and fitness requirements. Other matters which emerged that related to these areas, were their experiences prior to going on maternity leave and during maternity leave.

There was consensus among the groups that there was a lack of pre maternity information relating to healthcare, fitness and who they could get advice from in the early stages of pregnancy. All participants adopted a find it yourself approach. This was described by one participant "What you would do is touch base with other people who would have had kids and get it from them" (FG1P2), "if you were one of the first people in an area to have a child, you were snookered" (FG2P6). It was acknowledged that there was a Defence Force Maternity Policy and Defence Force Regulations which covered leave entitlements. These were deemed to be helpful. The experiences in relation to accessing information was different for commissioned and non-commissioned officers. Non-commissioned officer's felt that their knowledge of Defence Force Regulations was limited in depth when compared to commissioned officers. They also felt that access to this information would be more difficult for female Private soldiers and those who may not have computer access at work. All participants agreed that "you had to takean active role in manging it. It's your responsibility" (FG1P1).
Administration of leave entitlements was similarly managed by the women themselves. The male senior management wouldn't be familiar with it because they never had to be. I do remember saying to the adjutant at the time this is the application you have to do A, B, C, D, and it has to go to Galway and it has to go to COMO. So it was that you had to tutor them on what to do. (FG1P2)

The administration of entitlements and access to information in this context is not something which was discussed in the literature.

There was little contact between the focus group participants and the Defence Forces while they were on maternity leave. Informal female networks and spouses from the Defence Forces were utilised to access the organisation. "We have a WhatsApp group for all the females so if there were a few courses coming up you would have said look I'm heading off on maternity leave you might keep your ear to the ground" (FG1P1). 
Uncertainty over posting after maternity leave was an issue identified that concerned commissioned officers only. However, it was largely accepted that uncertainty over future postings in the Defence Forces was considered normal practice, although this does not diminish it as a source of stress. The issue of uncertainty around postings in general was also identified by the senior HR manager in the Defence Forces as something that needs to change across the Defence Forces.

The need for a supportive work environment on return to work was seen to be key for many as this was identified as key to many other issues. "It's all down to the Commanding Officer really they kind of set the tone, they put you at ease and if they have experienced family life themselves then they can empathise a little bit and that really helps" (FG2P6). LuciaCasademunt et al (2018) and Barrett (2018) focus on the importance of support and the key role that exists for supervisors helping women to transition back to work. A supportive boss was identified as source of strength and even something that could be linked to developing resilience to enable women to think about the future. While for the most part the participants cited supportive environments on return, specific examples of bosses who acted as mentors were the exception rather the rule.

He kind of coached me like a mentor. I remember coming in a few days after starting back and saying I'm stressed out and him saying don't quit and saying the kids will be in school and you will be sitting at home bored. I was lucky some of my other colleagues have horrible relationships with their bosses. (FG1P5)

This is consistent with the findings of Gatrell (2013) where she states that none of the women in her research provide evidence of proactive career support. The feelings of apprehension and the rebuilding of confidence on return to work fit with the themes which Grether, Sowislo and Wiese (2017) identify. These authors discuss how insecurity and ambiguity underpin transition phases such as return to work from maternity leave. This is something that is not unique to the Defence Forces. "Women often experience significant isolation on returning and just do not feel safe to have those conversations in their immediate work location" (Senior HRM HSE).

Having your first one it is life changing. You're all over the place, being off for the first time since starting work and you have no idea how to come back into it. It is very difficult coming back I don't think that they appreciate it at all. You're just back in. Yes, leaving the kid for the first time it is hard. (FG2P3)

The physical aspects of returning to work were raised in the context of breast feeding and fitness testing. Breast feeding was not a topic of contention and featured only within one focus group. One example was provided within this focus group linking the Defence Forces Women's network to the upgrade and provision of facilities for returning mothers who sought to continue to breastfeed. This concurs with research undertaken by Galinsky and Stein (1990) where supportive work environments can improve the quality of the experience for the returning employee. It echoes Morrissey (2018) where she notes the necessity and importance of women supporting women. 
None of the participants identified any physical difficulties from pregnancy which would have prevented them from returning to physical training. Returning to full fitness and passing the Defence Forces fitness test was discussed and considered a personal responsibility. There was no formal fitness support provided to any of the participants. It was primarily reliant on good will and the individual woman's initiative. "The Orderly Sergeant said listen you're only back, I don't know what you have been doing at home. You go do your own thing, which was great. I was 24 at the time going out running with a group 19-year olds thinking how I am going to keep up with these lads" (FG1P4). It was highlighted by some focus group members that Defence Force physical instructors did not receive any specific training in relation to engaging with women returning to physical training after maternity leave. Several women spoke of the benefit of private physiotherapy they had received.

\section{The unforeseen consequences of becoming a mother}

A range of sub themes emerged which when analysed were grouped under the theme of the unforeseen consequences of becoming a mother. Those categorised here, include changes to previously held views around career, self-limiting choices, concerns over performance appraisal, accessibility and structure of career courses and the crossover of mother role into work.

All the participants admitted that their assessments of their future careers had changed on becoming a mother. This is in keeping with research conducted by Heneghan (2012), Cahusac and Kanji (2014) and Carroll (2018). They also revealed a very deep personal held responsibility for any decisions around their careers going forward. "The opportunity is there and nobody is stopping you from doing it. It is a choice that I have to make as a mother" (FG1P1).

Don't get me wrong. If I was to say before I had kids would that be the way. Back in the day you were gung-ho and wanted to do the best that you could do but then the situation changes and that's it. It is not an easy thing to swallow and then when your peers in your vintage are moving on that's hard to take. (FG1P2)

Interestingly the majority of the participants focused on all the reasons not to pursue further promotion after a certain point. They did not outline any of the reasons to go for promotion or describe how they might overcome the huddles on the path to promotion. "I completely understand what is required if you do go forward for promotion, I am ok with that and I have made a conscious decision that I will not do it because of what is expected" (FG1P1). This demonstrates what Sandberg (2013), Morrissey (2018) and Portas (2018) describe as selflimiting decisions. It highlights that women display a commitment where they see the full picture and not the individual pieces. This could prevent women from reaching their full potential. An approach where one step at a time was considered by itself, could have an impact on the future career prospects of women and extend the time in which they must make big career decisions. This does not minimise the difficulty associated with career progression and motherhood.

The structure and accessibility of courses required for career progression for both 
commissioned and non-commissioned officers was a topic of importance. Associated with this was the requirement to accumulate points from other courses to aid selection for career courses for non-commissioned officers.

I know the physical effects of child birth might restrict females from applying for certain physical type courses as they are physically not able to do it, and a lot of these physical courses are over five days in duration which amount to more points for selection for career courses. (FG1P4)

Both Harris (2009) and Heneghan (2012) point to the difficulty for women when they have to negotiate male career paths. The modernisation of the Joint Command and Staff Course was viewed as a progressive step. Although there was confusion as to why the course had not yet been advertised in this manner. It was suggested that this model could potentially increase access to career courses for non-commissioned officers. It was further proposed that these courses could be restructured into a ground phase and an academic phase to accommodate a modulated approach. The senior HR manager in the Defence Forces also made observations relating to the numbers of officers who had completed these courses that were mothers.

I would say it is probably more in the area of feasibility for people. What they can do given their own personal circumstances given their own family structure, given where they live and the duration of the course. People are having their families a little later in life than they would have in the past which is probably not making it easier of that particular group to undertake a long course away from home. (Senior HRM DF)

It was observed that there were no suggestions from the Senior HR manager in the DF as to how career course structures could be moderated to address this feasibility issue.

Performance appraisal relating to maternity leave was an area of concern for both commissioned and non-commissioned officers. This was not an area that featured explicitly in the literature; however, it can be directly associated with career progression brought to the fore by Hewlett (2007) and Barrett (2018). Both groups' felt that absence from work due to maternity leave had a negative effect on your next promotion competition. It was also raised that the timing and number of pregnancies could affect the extent of this impact. Some of the examples cited could be described as discriminatory practice.

I think maternity leave has a very negative impact on your career progression especially from Capt to Comdt... Because they got that year on me when I was not there, I missed an AF451. I didn't really have a chance; I may as well have not sat the interview. (FG2P4)

In my Brigade there is an unwritten rule that you must do a minimum of six months in a unit to be considered for an excellent rating. However, you are legally obliged to leave the organisation two weeks before your due date which may be under six months. Then technically you can't get a particular rating.... just because you're pregnant does not mean you can't perform excellently. (FG1P1) 
Some participants described how while on maternity leave, they had undertaken additional education. Some of this study related to new roles they would perform on return to work and further demonstrates the commitment felt by these women to give their absolute best to the Defence Forces.

For my recent promotion competition, I wrote two covering letters to cover those two periods I had been away on maternity leave and I felt as though I had to write those... I was on maternity leave and justifying while I was on maternity leave that I had done a post graduate qualification. (FG2P1)

The concerns raised above relating to performance appraisal were acknowledged by the Senior HR manager in the Defence Forces as potentially putting women at a disadvantage. However, while he confirmed that no specific guidance exists for interview boards on how to address this matter, he was confident in the overall training and experience of the board members, that they would do their best to treat all candidates fairly.

A subtheme that emerged related to the transfer of a women's caring attributes from home as the result of becoming a mother to her role in work. Carroll (2013) discussed this in detail emphasising the softer female leadership skills of empathy and emotional intelligence.

All their concerns were neglected over the last four or five years mainly due to the fact that it was a male officer there. Some students have come to me with enormous problems they never had the opportunity to say it before or felt they could not raise these issues with a man which is a bit strange as they are all men. (FG2P1)

This cross over of roles is also associated with role overcrowding discussed by Harris (2009). "There are certain roles that you will be that mothering figure in one sense and the officer as well. It can be quite hard to strike that balance when you are at work" (FG2P3).

\section{Work life intersection: the new juggle}

Work life intersection is the space where work meets family. The term "the new juggle" was coined to capture the range of experiences described by the participants when navigating their life as both a mother and serving soldier. Issues around the need for flexibility and the consequences of it were dominant here. This relates directly to what Coser (1974) describes as the difficulty with engaging with more than one greedy institution. All women spoke of the appreciation for supports received and the intense desire to reciprocate and give back to the organisation for such support. This also bears out with Galinsky and Stein's (1990, p. 378) assertion "what the company gives it will get in return".

There was an absolute awareness that the work environment within which one worked greatly affected the ability to avail of flexible working practises. "You really appreciate the support you only look for what you absolutely need you do not take advantage." (FG1P1). Guilt for the necessity to avail of flexible work practises was acutely felt by the majority who had availed of it. This is consistent with the findings of Segal (1986), Harris (2009) and Vuga and Juvan (2013) and relates to the conflict again that arises when an individual is engaged with 
more than one organisation described as greedy (Coser, 1974).

Guilt was also experienced in relation to absence from home life and was identified by the participants to be something that they felt they experienced in a different way to their male partners. "It is just a different set of priorities. I do not think they feel guilt like we do. I don't think they bother about that plait in the hair or if someone has forgotten a lunchbox, I will be late for work to go back for the lunch box" (FG2P3). "I just don't think they see those kinds of things. Do they even know they are supposed to have a plait?" (FG2P2). This collates with Daalen, Willemsen and Sanders (2006) and supports the presence of gender differences in how men and women experience the work family intersection. Concerns over the time taken to administer parental leave applications and the effects on the management of childcare around this information vacuum were highlighted by several focus group members as sources of avoidable stress which added to their new juggle.

Access to flexible work practices, particularly parental leave, while categorised as a great support were flagged to come with a certain cost. Taber (2011), Cahusac and Kanji (2014) and Morrissey (2018) all concur with this. That cost being both observed and perceived by how those that availed of it, viewed their commitment to the job was altered in the eyes of others. "Ah she is just here for family. She is not here for any kind of seriousness; she is not here for that kind of thing" (FG2P1). "I could imagine how a person might perceive that. They might feel that they were thought less of" (Senior HRM DF). "I was told I couldn't do a Monday or a Friday, I could only do a Wednesday or a Thursday because he did not want the lads to think that I was having a long weekend. Even though it was unpaid and I was entitled to it" (FG2P3). All the women interviewed were eager to emphasize that when they availed of parental leave, they also worked through lunch breaks and additional hours at different times. They felt a duty to the organisation to get the work complete regardless of when.

\section{Defence Force management responses to motherhood}

The Defence Forces Maternity Policy lays out how a pregnant woman should be managed within the organisation. This policy was described by both management and the participants as a particularly good document. Awareness of the document at all levels and access by junior members to it was something that was noted. Some of the participants felt that they had to assist their superiors with how they were to be managed when they were pregnant. "I know there is a responsibility on individuals who find themselves pregnant to educate themselves in the area. But there is also an onus on management to acknowledge that they have both males and females working under them" (FG1P1). Coupled with this came the feeling expressed by some that a pregnant woman was seen as an inconvenience.

Family friendly appointments overseas were highlighted and welcomed by participants in this study. These are appointments of shorter duration. They were viewed as a particularly good option to accommodate both men and women, who due to family commitments and childcare restrictions were not in a position to complete a longer tour of duty overseas. A lot of discussion focused on the limited number of these appointments and the short lead in time for filling them. Several participants described how they now occupied a new space having become mothers where planning was central to how everything got done. It was suggested that longer lead in times for advertising these appointments would facilitate this planning and enable applications. Army participants explicitly expressed disappointment by the corps specific nature of the current family friendly appointments. 
The subject of mandatory selection for overseas service was particularly contentious for commissioned officers within both focus groups. Mandatory section is the process utilised to select individuals for overseas when no volunteers are forthcoming. The fact that family friendly appointments were not equated to overseas service when calculating mandatory selection was a source of anger and frustration for those effected. This was confirmed by the senior HR manager from the Defence Forces, to be the reality of the current situation. It was stated that this was something to which a solution was being sought but it was stressed that a solution was difficult.

When you are into mandatory selection someone is not going to be happy at the end of it and people will need if they are going to trust a mandatory selection policy even if they don't like it. If they are going to trust it, they have to see that it has a fair application. So, we have got to be careful about what we rule in and what we rule out, but a family friendly appointment is not currently within that marking scheme is something that we are aware of and something that we want to fix. (Senior HRM DF)

One issue that achieved consensus across both focus groups and both interviewees was the commitment and value that women bring to the workforce. Sandberg (2013) describes how women who return to work post maternity leave frequently do so with renewed energy. The Senior HR manager in the Defence Forces was very aware that 50 percent of the population were underrepresented in the Defence Forces and agreed with the participants that women added value to the organisation. "I think there is too much to be gained from female participation and minority participation for us not to seek to maximise it" (Senior HRM DF). The Senior HR manager in the HSE spoke about the establishment of a working group to focus on female participation at all levels within their organisation as a tool to address the underrepresentation of women and to maximise their potential. While they may be agreement on the value women bring, there were views within the focus groups that this value was not always appreciated by the Defence Forces.

Women work hard within the Defence Forces and they progress well and are really valuable employees. I think the organisation does not recognise that in us and that all of us are here to serve. They will see huge rewards back from female personnel if they were just to recognise that. (FG2P3)

Participants from all three services spoke of the under recognition of the value of women within the Defence Forces. This was linked to the apparent unwillingness of the organisation to recognise or adopt a female perspective on career courses and overseas service.

This study attempted to shine a light on an area that has not previously received attention. It focused on what happens when women who serve in the military become mothers. What are the unforeseen consequences of motherhood on career? Overall findings show that motherhood impacts both the individual and the organisation. The individual for the very first time has to cope with no longer behaving like a conceptual man as described by Snitow (1990). The organisation has to adapt to the new needs of the mother and provide additional supports. Motherhood ultimately alters the playing field and the organisation has a choice to make about levelling that playing field. The individual has a choice to make too but 
needs to be supported in that choice. The decisions made in respect of these choices by both the Defence Forces and the commissioned and non-commissioned female officers of the Defence Forces effect the overall capability of the organisation.

\section{PART FIVE. Conclusion}

\section{What happens when soldiers become mothers?}

The central hub of this discourse is about what happens when soldiers become mothers. The narratives provided by all the participants in this research suggest that motherhood is a time when women prioritise children and family over themselves. The time when women become mothers or shortly after, frequently coincides with the time when there exists a requirement to push forward with their careers. In the Defence Forces this includes the necessity to undergo career courses, deploy overseas or fill appointments at short notice which are often geographically far from home. This places women in a difficult position. All the women in this study were aware of this and were somehow preconditioned to deselect themselves from progressing within the organisation. This is perhaps for two main reasons. One, very few women have done it. There are only three senior female commissioned officers of Lieutenant Colonel rank or above and 13 senior female non-commissioned officers in the Defence Forces. Therefore, 1.6 percent of commissioned officers of the rank of Lieutenant Colonel and above are female and 2.4 percent of non-commissioned officers of the rank of senior NCO are female, a much smaller percentage of these are also mothers. The current popular expression in female literature comes to mind "if you can't see it you can't be it". Two, the organisation does not do anything to address the narrative that you have to choose between career and family. The majority of women choose family because a real choice is not on the table.

\section{What can the Defence Forces do to change?}

One of the means through which the Defence Forces could address the issue of women deselecting themselves is to acknowledge the importance of women within the organisation, to recognise the added value in terms of gender balance and gender diversity that women bring. As 50 percent of the women in the Defence Forces are mothers the issues around motherhood and the military are pivotal to achieving this gender balance and gender diversity. Every aspect of the military has been "shaped by men to the advantage of men" (Clear, 2017, p.47). Military career courses are not structured with family in mind. Family friendly overseas appointments do not carry any status. Efforts to date by the Defence Forces to address issues around women in the organisation could be described as tokenisms that have failed to dive into the cultural shift that is required.

The Defence Forces maternity policy was acknowledged by all who participated in this study to be a good document. However, it fails to address many issues that affect women after they become mothers. The supports received by women when they return to work after maternity leave are fundamental. This is a time when women struggle to juggle the many roles they have. It is also a time when women make decisions about their future careers. It is not the ideal time to make such decisions.

Women within this study spoke about their desire to serve and their continued commitment to the Defence Forces. They expressed a deep held gratitude for the statutory entitlements of paid and unpaid maternity leave and parental leave. They were keen to 
demonstrate their loyalty to the organisation and acutely felt the need to improve and develop themselves professionally even while on maternity leave. Investment in women is required to maximise the untapped potential offered by these women.

Finally, performance appraisal for both commissioned and non-commissioned officers is vitally important for career progression for both groups and for selection onto career courses for non-commissioned officers. The practice of restricting the overall rating received due to time is discriminatory to women who are either going on or returning from maternity leave.

\section{Recommendations}

In light of the conclusions above, the following recommendations appear relevant. When women return to work after maternity leave, they return to their roles as soldiers having undergone the biggest physical change to their bodies they may experience in their lives. It is important that the Defence Forces supports women. This can be achieved in a number of ways. All women returning to work should receive a mandatory physiotherapy consultation. They should also receive mandatory support with returning to physical training. To facilitate this, all physical training instructors should receive training in the physical fitness needs of women post pregnancy. The aim of such a program is to aid women returning to full physical fitness post pregnancy, to assist with regaining confidence and minimising injury.

A point of contact should be appointed within Units to act as a liaison for women going on maternity leave to maintain contact while on leave and to plan early for their return. Returning to work post maternity leave is challenging and a demanding transition period for women. A normalised phased return to work program acknowledging that an individual's circumstances have changed and providing support and advice on both the changes the individual and the organisation has undergone during this period. This type of program could be adapted to those returning from career breaks, leave of absence or indeed overseas deployments.

Both assessment and interview boards should be advised that absence due to maternity leave should not negatively affect female candidates. Women should be considered for career courses early. It is easier to navigate such courses prior to having children. Residential career courses are problematic to both men and women in the environment in which both partners now work. All career courses should be reviewed to consider the necessity for residential status and how they could be modularised.

The Defence Forces women's network requires investment. This network is an excellent mechanism to provide women with a formal tool to support each other within the Defence Forces. Unfortunately, it has not been adequately supported so far. Senior female commissioned and non-commissioned officers require mentoring and support. Expertise in this area is not available within the Defence Forces and should be sought externally.

\section{Further Research}

The participants in this research have pointed to several meaningful areas that are worthy of further consideration. These include the physical impact of pregnancy, the effect of spouse or partner support on future career and an evaluation of the Defence Forces female network. All 
of these suggestions in their own right are worthy of further attention and research. Perhaps the most intriguing area for further research is a comparable study looking at fatherhood and the military. This would be of value from a generational perspective with due examination of both senior, mid and junior Officers who are all fathers. The data collected during such a study might offer some surprising similarities regarding choices male officers are now making about their future careers and fatherhood. In a male dominated organisation such as the Defence Forces, action for change might be quicker when disassociated from women.

Overall, it is suggested that the topic of motherhood and the military within the Defence Forces would benefit from a study across all ranks with a focus on how the organisation might reflect a more female perspective. Such a study would provide fascinating insights into the world of women and work. It would also offer potential solutions to HR difficulties currently experienced by the Defence Forces.

The gender makeup of the Defence Forces consists of 94 percent men and six percent women. The diversity that exists amongst the 94 percent who are men is similarly represented within the six percent that are women. This provides a range of different experiences and viewpoints. A topic such as this clearly signals the differences that exist between men and women. When attention is drawn to such a subject the potential for negative comment exists. However, it is important to recognise there are differences between men and women. These differences do not equate to different abilities to perform as serving soldiers in the Defence Forces, but they do require attention and management. If the Defence Forces wants to recruit, retain, promote and increase the number of women within the organisation it is essential that it gives due cognisance to what these women need and want. Failure to do so will continue to result in a loss of capability which the Defence Forces cannot afford. Progress requires an acceptance that we can be equal but different (Morrissey, 2018).

Please note that the views expressed in this article are those of the author alone and should not be taken to represent the views of the Irish Defence Forces, the Command and Staff School or any other group or organisation.

\section{BIBLIOGRAPHY}

Acker, J. (1990). Hierarchies, jobs, bodies: A theory of gendered organisations. Gender and Society, 4(2), pp. 139-158.

Apostu, I. (2017). Female Management- Between Motherhood and Career. Ecoforum.

Ashforth, B., Kriener, G. and Fugate, M. (2000). All in a day's work: Boundaries and micro role transitions. The Academy of Management Review, 25(3), pp. 472-491.

Baran, B., Rhoades Shanock, L. and. Miller, L. (2012). Advancing organisational support theory into the twenty-first century world of work. Journal of Business Psychology, 27(2), pp. $123-147$.

Barrett, E. (2018). How Can The Irish Naval Service Retain Their Senior Female 
Officers?. Unpublished MSc (HRM) thesis: University of Limerick.

Beacom, A. (2013). The Retain Maternity Leave Transition Coaching Model: Applying Schossberg's Transition Theory to Create a New Model of Executive Coaching. Unpublished Phd (Education) thesis: Columbia University.

Betz, N. and Fitzgerald, L. (1987). The Career Psychology of Women. London: Academic Press INC.Bryman, A. and Bell, E. (2015). Business Research Methods (4th edn.), New York: Oxford.

Bussell, J. (2008). Great expectations: can maternity coaching affect the retention of professional women?. International Journal of Evidence Based Coaching and Mentoring, Issue 2, pp. 14-26.

Carroll, M. (2013). A Few Good Women: Female Leadership in the Irish Defence Forces.

Unpublished MA (LMDS) thesis: Maynooth University.

Carroll, N. (2018). National HSE Research: Engagement and Experience of Working Parents in the HSE on return to work from birth/adoption of a child, Dublin: Health Service Executive.

Cahusac, E. and Kanji, S. (2014). Giving up: How gendered organisational culturespush mothers out. Gender, Work and Organisation, 21(1), pp. 57-70.

Clark, S. (2000). Work/family border theory: A new theory of work/family balance. Human Relations, 53(6), pp. 747-770.

Clear, O. (2017). Why Women Join: A Perspective on Gender and the Irish Defence Forces. Unpublished MA (LMDS) thesis: Maynooth University.

Connell, R. and. Messerschmidt. J. (2005). Hegemonic Masculinity: Rethinking the concept. Gender and Society, pp. 829-859.

Coser, L. (1974). Greedy Institutions Patterns of Undivided Commitment. New York: The Free Press.

Daalen, G., Willemsen, T. and. Sanders, K. (2006). Reducing work-family conflict through different sources of social support. Journal of Vocational Behaviour, Volume 69, pp. 462476. 
Defence Forces. (2015). General Routine Order 04 of 2015. Dublin: Defence Forces Printing Press.

Department of Defence. (2015). White Paper on Defence. Dublin: Defence Forces Printing Press.

Department of Defence and Defence Forces. (2017). Annual Report. Dublin: Defence Forces Printing Press.

Department of Defence and Defence Forces. (2019). Annual Report. Dublin: Defence Forces Printing Press.

Department of Justice and Equality. (2017). National Strategy for Women and Girls 20172020. Dublin: Department of Justice and Equality.

Desrochers, S. and Sargent, L. (2004). Boundary/border theory and work family integration. Organisation Management Journal, 1(1), pp. 40-48.

Eisenberger, R. (1986). Perceived organisational support. Journal of Applied Psychology, pp. $500-507$.

Galinsky, E. and Stein, P. (1990). The impact of human resource policies on employees balancing work/family life. Journal of Family Issues, 11(4), pp. 368-383.

Gatrell, C. (2013). Maternal body work: How women managers and professionals negotiate pregnancy and new motherhood at work. Human Relations, 66(5), pp. 621644.

Glazer, S. (2006). Social support across cultures. International Journal of Intercultural Relations, 30(5), pp. 605-622.

Goffman, E. (1961). Asylums. New York: Anchor Books.

Grether, T., Sowislo, J. and Wiese, B.S. (2017). Top-down or bottom-up? Prospective relations between general and domain-specific self-efficacy beliefs during awork-family transition. Personality and Individual Differences, pp. 131-139.

Hall, D. (1971). A theoretical model of career sub identity developing in organisational settings. Organisational Behaviour and Human Performance, Volume 6, pp. 50-76.

Hall, D. (1972). A model of coping with role conflict: The role behaviour of college educated women. Administration Science Quarterly, 17(4), pp. 471-486.

Harris, G. (2009). Women, the military and academe navigating the family track in an up 
and out system. Administration and Society, 41(4), pp. 391-422.

Heneghan, H. (2012). The Decision Point: Why Female Officers Opt Out of a Career in the Defence Forces. Unpublished MA (LMDS) thesis: Maynooth University.

Hewlett, S. (2007). Off-Ramps and On Ramps: Keeping Talented Women on the Road to Success. Boston: Harvard Business School Press.

Huffman, A., Culbertson, S. and Barbour, J. (2015). Gender roles in a masculine occupation: Military men and women's differential negotiation of the workfamily interface. In Mills, M, J. (2015) (ed) Gender and the Work-Family Experience: An Intersection of Two Domains. New York: Springer International.

Hughes, D. and Galinsky, E. (1988). Balancing work and family life: Research and corporate application. In: Maternal Employment and Children's Development: Longitudinal research. New York: Plenum, pp. 233-268.

Ireland. (1994). Maternity Protection Act 1994. Dublin: Stationary Office.

Ireland. (1994). Statutory Instrument 446/1994 Safety, Health and Welfare at Work (Pregnant Employees) Regulations, 1994. Dublin: Stationary Office.

Ireland. (2004). Maternity Protection (Amendment) Act, 2004. Dublin: Stationary Office. Ireland. (2006). S.I. No.51/2006 Maternity Protection Act 1994 (Extension of Periods of Leave) Order 2006. Dublin: Stationary Office.

Kahn, R., Wolfe, R., Quinn, R., Snoek, J. and Rosenthal, R. (1964). Organisational Stress. New York: Wiley.

Kanter, R. (1977). Men And Women of the Corporation. New York: Basic Books.

Kelly, E., Kossek, E., Hammer, L., Durham, M., Bray, J. and Chemack, K. (2008). Getting there from here: Research on the effects of work-family initiatives on work- family conflict and business outcome. The Academy of Management Annals, Volume 2, pp. 305-49.

Killian, L. (1952). The significance of multiple-group memberships in disaster. American Journal of Sociology, Volume 57, pp. 309-314. 
Kronsell, A. (2005). Gendered Practices in Institutions of Hegemonic Masculinity. International Feminist Journal of Politics, 7(2), pp. 280-298.

Kurtessis, J., Eisenberger, J., Ford, M., Buffardi, L., Steward, K. and. Adis, C. (2015). Preceived organisational support: A meta-analytic evaluation of organisational support theory. Journal of Management, pp. 1-31.

Lahelma, E., (2005). Finding communalities, making differences, performing masculinity: Reflections of young men on military service. Gender and Education, 17(3), pp. 305-317. Langan, D., Sanders, C. and Agocs, T. (2017). Canadian police mothers and the boy's club: Pregnancy, maternity leave and returning to work. Women and Criminal Justice, pp. 235249.

Lewis, P. and Simpson, R. (2012). Kanter revisited: Gender, power and (in)visibility. International Journal of Management Reviews, Volume 14, pp. 141-158.

Levinson, D. (1959). Role, personality and social structure in the organisational setting. Journal of Abnormal and Social Psychology, pp. 170-180.

Levinson, D. (1996). The Seasons of a Woman's Life. New York: Morrow.

Lucia-Casademunt, A. M., Garcia-Cabrera, A. M., Padilla-Angulo, L. and Cuéllar-Molina, D. (2018). Returning to work after childbirth in Europe: Well-Being, work-life balance, and the interplay of supervisor support. Frontiers in Psychology, pp. 1-10.

Meglich, P., Mihelic, K. and Zupan, N.(2016). The outcomes of perceived work- based support for mothers: A conceptual model. Management, Volume 21, pp. 21-50. Morf, M. (1989). The Work/Life Dichotomy. New York: Quorum Books. Morgan, D. (1998) Planning Focus Groups. CA: Sage Publishers.

Morrissey, H. (2018). A Good Time to be a Girl. London: William Collins.

Netemeyer, R. (1996). Development and validation of work- Family conflict scales. Journal of Applied Psychology, 81(4), 400-410.

Perrott, T. (2015). Beyond 'token' firefighters: Exploring women's experiences of gender and identity at work. Social Research Online, 21(1), pp.1-14,[online], available: www.socialresearchonline.org.uk [15 May 2019].

Portas, M. (2018). Work Like a Woman. London: Bantam Press. 
Ranson, G. (2005). No longer "one of the boys": Negotiations with motherhood, as a prospect or reality, among women in engineering. The Canadian Review of Sociology and Anthropology, 42(2), pp. 145-166.

Raskin, P. (2006). Women, work and family three studies of roles and identity among working mothers. American Behavioural Scientist, 49(10), pp. 1354-1381.

Repetti, R. (1987). Individual and common components of the social environment at work and the psychological well-being. Journal of Personality and Social Psychology, 52(4), pp. 710-720.

Rhoades, L. and Eisenberger, R. (2002). Perceived organisational support: A review of the literature. Journal of Applied Psychology, pp. 698-714.

Robson, C. (2002) Real World Research: A Resource for Social Scientists and Practitionerresearchers. Oxford: Blackwell Publishers.

Ryan, A. (2015a) Post-Positivist approaches to research. In: T. Walsh and A. Ryan, (eds.) Writing your thesis: A guide for postgraduate students. Dublin: Mace Press, pp. 23-37. Ryan, A. (2015b) Methodology: Collecting data. In: T. Walsh and A. Ryan, (eds.) Writing your thesis: A guide for postgraduate students. Maynooth: Mace Press, pp. 117-138. Sandberg, S. (2013). Lean In: Women, Work and the Will to Lead. New York: Elbury Publishing.

Sasson-Levy, S. (2011). The military in a globalised environment: Perpetuating an extremely gendered organisation. In Jeanes, E., Knights, D. and Yancey Martin, P. (2011) (eds) Handbook of Gender, Work and Organisation. New Jersey: Wiley and Sons.

Schieman, S. and Gavin, P. (2008). Trouble at the Border?: Gender, flexibility at work and the work-home interface.. Social Problems, 55(4), pp. 590-611.

Segal, M. (1986). The military and the family as greedy institutions. Armed Forces Society, 13(1), pp. 9-38.

Snitow, A. (1990). A gender diary. In: Hirsch, M. and Fox Keller, E., (eds) Conflicts in Feminism. New York: Routledge. 
Soeters, L., Winslow, D. and Weibull, A. (2003). Military culture. In: G. Caforio, (ed) Handbook of the Sociology of the Military. New York: Academic/Plenum Publishers, pp. 237-254.

Southwell, K. and MacDermid Wadsworth. S. (2016). The many faces of military families: unique features of the lives of female service members. Military Medicine, 181(1), pp. 70-79.

Stenbacka, C. (2001). Qualitative research requires quality concepts of its own.

Management Decision, 39(7), 551-555.

Steward, D., Shamdasani. P. and Rook, D. (2007) Focus Groups. (2nd edn.), Thousand Oaks: Sage.

Taber, N. ( 2009). Gender in children's books written for military families: The gendered portrayal of women and men, mothers and fathers in the Canadian military. Journal of Integrated Social Sciences, 1(1), pp. 120-140.

Taber, N. (2011). "You better not get pregnant while you're here": tensions between masculinities and femininities in military communities of practice. InternationalJournal of Lifelong Education, 30(3), pp. 331-348.

Yoder, J. (1991). Tokenism. Gender and Society, pp. 178-192.

Vuga, J. and Juvan J. (2013). Work-family conflict between two greedy institutions-the family and the military. Current Sociology, 61(7), pp. 1058-1077. 